\title{
Management of cases of COVID-19 infection with acute respiratory failure: a narrative review
}

\author{
Omar Rezk Alshaer ${ }^{1 *}$, Abdullah Obaid Binobaid ${ }^{1}$, Ruzan Mohammed Saleh², \\ Abdelrahman Abdrabou Eldabbari ${ }^{3}$, Nasser Ibrahim Aldawsari ${ }^{4}$, \\ Mubarak Mohammed Alasmari ${ }^{5}$, Abdulkarim Thumail Alshamry ${ }^{5}$, Aisha Nour Almutairi, \\ Musab Salem Alluqmani ${ }^{6}$, Rayan Saeed Alzahrani ${ }^{7}$, Mohammed Mana Alqahtani ${ }^{8}$
}

\begin{abstract}
${ }^{1}$ Department of Internal Medicine, Security Forces Hospital, Riyadh, Saudi Arabia
${ }^{2}$ Department of Internal Medicine, King Fahad General Hospital, Jeddah, Saudi Arabia

${ }^{3}$ Department of Internal Medicine, Dr. Sulaiman Al-Habib Al-Takhassussi Hospital, Riyadh, Saudi Arabia

${ }^{4}$ College of Medicine, Vision Colleges, Riyadh, Saudi Arabia

${ }^{5}$ College of Medicine, AlMaarefa University, Riyadh, Saudi Arabia

${ }^{6}$ College of Medicine, Qassim University, Al Malida, Saudi Arabia

${ }^{7}$ College of Medicine, Al-Maarefa University, Riyadh, Saudi Arabia

${ }^{8}$ Armed Forces Hospitals Southern Region, Khamis Mushait, Saudi Arabia
\end{abstract}

Received: 08 April 2021

Revised: 02 May 2021

Accepted: 03 May 2021

*Correspondence:

Dr. Omar Rezk Alshaer,

E-mail: Zina.alzahidy@hotmail.com

Copyright: () the author(s), publisher and licensee Medip Academy. This is an open-access article distributed under the terms of the Creative Commons Attribution Non-Commercial License, which permits unrestricted non-commercial use, distribution, and reproduction in any medium, provided the original work is properly cited.

\begin{abstract}
Corona viruses are enveloped, positive-sense, single-stranded large RNA viruses that affect humans and many animals. About 5\% of COVID-19 patients need ICU admission due to ARDS, with a case fatality rate varying from $30 \%$ to $60 \%$. Some patients need help other than supplementary oxygen, such as non-invasive ventilation or intubation. Before deciding the appropriate respiratory support for acute respiratory failure patients, concerns regarding the dangers of various treatments should be considered. During the treatment of COVID-19 patients, all respiratory therapies face a risk of aerosol-generating procedures. When treating COVID-19 patients, the priority and consideration should be personal safety devices and environmental control/engineering.
\end{abstract}

Keywords: COVID-19, Acute respiratory distress syndrome, Corona pandemic, Oxygen therapy

\section{INTRODUCTION}

A series of pneumonia cases of unexplained causes erupted in Wuhan, China, by the end of $2019 .{ }^{1}$ A few weeks later, deep sequencing analysis of lower respiratory tract samples a few weeks later, in January 2020 , identified a novel virus, severe acute respiratory syndrome coronavirus-2 (SARS-CoV-2), as the causative agent for the detected pneumonia cluster. On February 11,2020 , the world health organization (WHO) called the epidemic caused by SARS-CoV-2 the new Coronavirus disease-2019 (COVID-19). By March 11, 2020, the WHO announced the pandemic status when the number of countries affected was 114 , with more than 118,000 cases and over 4000 deaths. $^{2}$

Coronaviruses were first observed and described by Tyrell and Bynoe in 1966. Coronaviruses are enveloped, positive-sense, single-stranded large RNA viruses that affect humans and many animals. ${ }^{3}$ Within the time of 
writing (March 30 2021), the COVID-19 pandemic has affected 223 countries, with more than 127 million confirmed cases and 2.79 million confirmed deaths estimated and recorded throughout the world., ${ }^{4,5}$

COVID-19 clinical symptoms range from asymptomatic or paucisymptomatic types to extreme respiratory failure necessitating mechanical ventilation and assistance in an intensive care unit (ICU) to multi-organ and pathological manifestations such as septic shock, sepsis, and multiple organ dysfunction syndromes (MODS). ${ }^{6}$

The time period from COVID-19 onset of symptoms to death varies from 6-41 days with a median range of 14 days. ${ }^{6}$ This period is determined by the patient's age and immune system status. Fever, cough, and nausea are the most frequent signs of COVID-19 disease, but other symptoms include sputum formation, headache, dyspnea, diarrhea, and lymphopenia. $^{7}$

According to the WHO, COVID-19 has an incubation period of 2 to 10 days. However, some evidence showed that the incubation period may last longer than two weeks and that a very long incubation period can represent double exposure. ${ }^{7}$ Many reports prescribe a 14 day medical treatment duration for people who have been exposed to the pathogen. The magnitude of the clinical picture seems to be linked to age ( $>70$ years), comorbidities such as diabetes mellitus (DM), asthma, and chronic obstructive pulmonary disease (COPD); however, no clinically-based hypotheses have been established at this point. 8,9

COVID-19 infections cause severe respiratory failure, which results in acute hypoxemia associated with overt pulmonary shunting and severe ventilation/perfusion. ${ }^{10}$ Nevertheless, the precise mechanism of respiratory failure is unknown. There is evidence that pulmonary microvascular thrombosis caused by thromboinflammation can significantly contribute to respiratory decompensation in these patients. ${ }^{11}$

About 5\% of COVID-19 patients need ICU admission due to acute respiratory distress syndrome (ARDS), with a case-fatality rate varying from $30 \%$ to $60 \% .^{8-11}$ Most patients require invasive artificial ventilation to treat gas exchange abnormalities, and it is the mainstay of supportive therapy. Mechanical ventilation is used in this situation to restore sufficient gas exchange while limiting ventilator-induced lung damage (VILI). ${ }^{12}$ Proper ventilatory treatment during ARDS decreases the risk of VILI and is one of the potentially modifiable variables capable of enhancing survival. ${ }^{13}$

This narrative review highlights and summarises the recent literature on the association between COVID-19 infection with acute respiratory failure and its management besides the possible risk factors and pathophysiology.

\section{RISK FACTORS AND COMORBIDITIES}

In a new study of 25 trials, including 4881 extreme and non-severe COVID-19 cases, the main prevalent comorbidities of affected patients were hypertension (prevalence of about $33 \%$ vs. $22 \%$ in severe versus nonseverely infected patients) and diabetes (with a prevalence of about $14 \%$ among severely infected patients while $9 \%$ prevalence in non-severely affected patients). ${ }^{14}$ Another study found that advanced age, male gender, and underlying comorbidities such as hypertension, obesity, chronic obstructive lung disease, diabetes, coronary, hepatic, and/or renal disease, immunodeficiency, malignancy, and pregnancy were important risk factors for the COVID-19 progression to moderate, i.e., critical disease. ${ }^{15}$

\section{PATHOPHYSIOLOGY}

In the simplest possible manner to ensure viability, respiratory failure is defined as the utilization of oxygen supplementation or mechanical ventilation, with the grading of severity in accordance with the maximum respiratory assistance obtained at any stage during hospitalization (non-invasive ventilatory support, extracorporeal membrane oxygenation, supplemental oxygen therapy only or invasive ventilatory support). ${ }^{16}$

Both the onset of extreme respiratory failure and mortality have been attributed to an overly aggressive host immune response. ${ }^{6,8,17}$ This has enhanced interest in COVID-19 immuno-modulatory therapy. ${ }^{18,19}$ However, it is debatable whether it is acceptable to attribute the severity of COVID-19-related respiratory failure to cytokine storm syndrome, owing to a lack of prospective evidence is seriously ill COVID-19 patients. ${ }^{20}$ There is a significant gap in COVID-19 pathophysiology because the major impairment of respiratory function and elevations in inflammatory cytokines will be reasonably anticipated to occur in chronically ill patients, a population in which the majority of mortality occurs, posing a significant resource challenge on healthcare systems. ${ }^{12}$ Given their central function in inflammatory signaling cascades and readily accessible immunomodulatory therapies that target their particular activities, interleukin (IL)-6, IL-1, and tumor necrosis factor (TNF) have emerged as possible targets. ${ }^{18}$

A multi-centre study investigated immune dysregulation among 54 European patients (28 of them with acute severe respiratory failure). Many of the patients had clinical characteristics consistent with macrophage activation syndrome (MAS), including low CD19+ Bcells, CD4+ T-cells, and NK cells. TNF and IL-6 levels were also found to be consistently elevated, indicating a hyperactive monocyte-macrophage system. ${ }^{21}$ Histological changes in COVID-19 pneumonitis revealed pauciinflammatory septal capillary injury with prominent septal capillary fibrin deposition and neutrophil infiltration of alveolar septa. ${ }^{22}$ There was no 
evidence of viral cytopathic or classical ARDS modifications such as diffuse alveolar damage with hyaline membranes or type II pneumocyte hyperplasia. Terminal complement components C5b-9, C4d, and mannose-binding lectin-associated serine protease (MASP) were found in the microvasculature, indicating activation of the alternative and lectin-based complement pathways. Another analysis of ten patients' lung autopsies reported mainly proliferative diffuse alveolar injury, epithelial viral cytopathic effects of small airway epithelium, but limited lymphocytic infiltration. ${ }^{23,24}$

\section{MANAGEMENT}

The principle that ARDS is a heterogeneous syndrome with variable mechanical and gas exchange disruptions is a significant but common discovery that is as old as the definition of ARDS itself. This therapeutic and biological variation adds greatly to the difficulty of managing the syndrome. When it comes to the different medication effects, heterogeneity is scientifically important. Positive end-expiratory pressure (PEEP) strategy levels and fluid control, for example, can react differently to hyperinflammatory versus hypo-inflammatory sub-phenotypes. 25,26

Identifying recruitability with a simple bedside technique could tailor ventilatory treatment in ARDS patients, particularly those with COVID-19. However, the use of such a tailored physiological strategy does not always mean better treatment outcomes. ${ }^{27}$ Similarly, an atypical ARDS presentation does not always imply that the patient will react differently to a standard care regimen. ${ }^{28}$

\section{OXYGEN THERAPY}

The mild dyspnea encountered by certain patients with demonstrable hypoxemia has generated discussion over the importance of oxygen therapy. However, hypoxemia is a weak inducer of dyspnea, and the difference of symptoms related to hypoxemia is unsurprising. Even for affected patients with minor symptoms, there is little evidence to suggest tolerating hypoxemia. A new randomized study comparing liberal (aim oxygen saturation 96\%) and conservative (target 88-92\%) oxygen therapy methods in patients with ARDS were interrupted early after it became apparent that the conservative strategy was unlikely to support patients and could hurt them. ${ }^{29,30}$ In adults with covid-19, maximum oxygen saturation of $92-96 \%$ is recommended, with supplemental oxygen if required. ${ }^{31}$

Some patients will need help other than supplementary oxygen, and the determination between a high flow nasal cannula, non-invasive positive pressure ventilation, or early intubation was controversial. Concerns about the required protection for healthcare personnel from viral aerosols exposure while providing the best quality of care for patients should be put into consideration. ${ }^{31}$

\section{NON-INVASIVE VENTILATION}

Non-invasive positive pressure ventilation (NIPPV) allows patients to stay conscious by providing ventilatory assistance without using an endotracheal airway. Although this method is non-invasive, it is not entirely risk-free. Patients maintain some control of their breathing. Large volume breaths may result in selfinflicted lung damage, which was linked to higher rates of mortality for patients admitted to an ICU with ARDS. ${ }^{32,33}$

NIPPV is related to a variable and difficult-to-quantify risk of aerosol production, which can be influenced by the seal's tightness over the patient's mask. Non-invasive ventilation is the potential for limited use in patients with hypoxemic respiratory failure caused by COVID-19, given the patients' uncertain risk. ${ }^{34}$

\section{INTUBATION}

Debates about and against early intubation remain unresolved, owing to a lack of sufficient proof. Those who advocate immediate intubation contend that it decreases the risk of self-inflicted lung damage. Many that oppose early intubation point to the high mortality rates recorded among incubated patients with COVID-19, as well as fears that ventilator-induced lung damage is a factor. The right solution would most certainly differ based on the patient. A single strategy is not likely to be successful in a disease as complex as COVID-19. ${ }^{31,35}$

Since ARDS induced by COVID-19 is similar to other forms of ARDS, the principles governing ventilation should be the same: providing ventilation to preserve the lungs with low driving pressures, low tidal volumes, and titration of PEEP to satisfy each patient's needs, with the general aim of enhancing lung compliance. Significant data suggest that protective ventilation with lower tidal volumes and pressures is closely correlated with better outcomes in ARDS patients. ${ }^{36}$ A systematic analysis found that tracheal intubation was the most consistent relationship with an elevated risk of SARS transmission to professionals; mask ventilation was also strongly correlated (only two studies), but the results were not deemed rigorous enough to draw strong conclusions. ${ }^{37}$

COVID-19 treatment recommendations differ from country to country. The WHO guidelines are very broad, suggesting symptom management and cautioning physicians when treating children, pregnant women, and patients with underlying co-morbidities. There is no approved treatment for COVID-19; instead, supportive care is recommended based on the needs of each patient (e.g., antipyretics for fever, oxygen therapy for respiratory distress). Furthermore, according to WHO guidelines, extreme cases should be treated with empiric antibiotics, with artificial ventilation being used depending on the patient's clinical condition. Since they had not yet been translated into English, some Asian 
guidelines (for example, the Japanese guidelines) were difficult to understand. ${ }^{38,39}$

Corticosteroids were previously mentioned in many studies; however, they are not prescribed in any guidelines. In the lack of conclusive scientific evidence, the WHO and the US center for disease control and prevention (CDC) has suggested that corticosteroids should not be used regularly in COVID-19 patients for treating viral pneumonia or ARDS unless they are indicated for other diseases like asthma or chronic obstructive pulmonary disease exacerbation, or sepsis. Short-term use of low to moderate doses of corticosteroids is recommended..$^{40,41}$

Around $80 \%$ of COVID-19 patients have mild disease and never need hospitalization, while about 5\% of patients become seriously ill, with ICU patients having the highest risk of ARDS. ${ }^{42}$ According to previous reports from China and recent ICNARC results from England, mortality was higher in those who needed mechanical ventilation than in those who did not and seems to be higher than in patients treated in ICU for other forms of viral pneumonia. The commonly used management for ARDS in COVID-19 has been in alignment with the normal approach, but treatment strategies for the atypical form of ARDS seen with COVID-19 need to be changed according to the characteristics of disease pathophysiology, allowing more incremental positive end-expiratory pressure adjustments. ${ }^{43}$

\section{CONCLUSION}

Before deciding the appropriate respiratory support for acute respiratory failure patients, concerns regarding the dangers of various treatments should be considered. During the treatment of COVID-19 patients, all respiratory therapies face a risk of aerosol-generating procedures. When treating COVID-19 patients, the first priority and consideration should be personal safety devices and environmental control/engineering. Within these conditions, it is unlikely that randomized clinical trials will be conducted to determine whether noninvasive respiratory assistance is superior for reducing the need for intubation in the sense of the COVID-19 pandemic.

Funding: No funding sources

Conflict of interest: None declared

Ethical approval: Not required

\section{REFERENCES}

1. Lu H, Stratton CW, Tang YW. Outbreak of pneumonia of unknown etiology in Wuhan, China: the mystery and the miracle. J Med Virol. 2020; 92(4):401-2.

2. World health organization director-general's opening remarks at the media briefing on COVID19-11 March 2020. Available at: https://www.who. int/dg/speeches/detail/who-director-general-sopening-remarks-at-the-media-briefing-on-covid19---11-march-2020. Accessed on 30 March 2021.

3. Tyrrell DA, Bynoe ML. Cultivation of viruses from a high proportion of patients with colds. Lancet. 1966:1(7428):76-7.

4. WHO Coronavirus disease (COVID-19) Dashboard. Available at: https://www.who.int/emergencies/ diseases/novel-coronavirus-2019. Accessed on 30 March 2021.

5. Lupia T, Scabini S, Pinna SM, Di Perri G, De Rosa FG, Corcione S. 2019 novel coronavirus (2019nCoV) outbreak: A new challenge. J Global Antimicrob Resist. 2020;21:22-7.

6. Wu C, Chen X, Cai Y, Zhou X, Xu S, Huang H, et al. Risk factors associated with acute respiratory distress syndrome and death in patients with coronavirus disease 2019 pneumonia in Wuhan, China. JAMA Int Med. 2020;180(7):934-43.

7. World Health Organization Covid-19 Infection. Available at: https://www.who.int/emergencies/ diseases/novel-coronavirus-2019. Accessed on 30 March 2021.

8. Zhou F, Yu T, Du R, Fan G, Liu Y, Liu Z, et al. Clinical course and risk factors for mortality of adult inpatients with COVID-19 in Wuhan, China: a retrospective cohort study. The lancet. 2020; 395(10229):1054-62.

9. Han W, Quan B, Guo Y, Zhang J, Lu Y, Feng G, et al. The course of clinical diagnosis and treatment of a case infected with coronavirus disease 2019. J Med Virol. 2020;92(5):461-3.

10. Zhang T, Sun LX, Feng RE. Comparison of clinical and pathological features between severe acute respiratory syndrome and coronavirus disease 2019. Chinese J Tuberc Respir Dis. 2020;43:E040-5.

11. Ciceri F, Beretta L, Scandroglio AM, Colombo S, Landoni G, Ruggeri A, et al. Microvascular COVID-19 lung vessels obstructive thromboinflammatory syndrome (MicroCLOTS): an atypical acute respiratory distress syndrome working hypothesis. Crit Care Resuscit. 2020;22(2):95.

12. Wu Z, McGoogan JM. Characteristics of and important lessons from the coronavirus disease 2019 (COVID-19) outbreak in China: summary of a report of 72314 cases from the Chinese Center for Disease Control and Prevention. JAMA. 2020;323(13):1239-42.

13. Grasselli G, Zangrillo A, Zanella A, Antonelli M, Cabrini L, Castelli A, et al. Baseline characteristics and outcomes of 1591 patients infected with SARSCoV-2 admitted to ICUs of the Lombardy Region, Italy. JAMA. 2020;323(16):1574-81.

14. Wang Z, Deng H, Ou C, Liang J, Wang Y, Jiang M, et al. Clinical symptoms, comorbidities and complications in severe and non-severe patients with COVID-19: A systematic review and meta-analysis without cases duplication. Medicine. 2020;99(48):56-9. 
15. Gao YD, Ding M, Dong X, Zhang JJ, Kursat AA, Azkur D, et al. Risk factors for severe and critically ill COVID-19 patients: A review. Allergy. 2021;76(2): 428-55.

16. Severe Covid-19 GWAS group. Genomewide association study of severe Covid-19 with respiratory failure. New Eng J Med. 2020;383(16):1522-34.

17. England JT, Abdulla A, Biggs CM, Lee AY, Hay KA, Hoiland RL, et al. Weathering the COVID-19 storm: lessons from hematologic cytokine syndromes. Blood Rev. 2020;15:100707-9.

18. Mehta P, McAuley DF, Brown M, Sanchez E, Tattersall RS, Manson JJ. COVID-19: consider cytokine storm syndromes and immunosuppression. Lancet. 2020;395(10229):1033-4.

19. Zumla A, Hui DS, Azhar EI, Memish ZA, Maeurer M. Reducing mortality from 2019-nCoV: hostdirected therapies should be an option. Lancet. 2020;395(10224):e35-6.

20. Leisman DE, Deutschman CS, Legrand M. Facing COVID-19 in the ICU: vascular dysfunction, thrombosis, and dysregulated inflammation. Intensive care medicine. 2020;46(6):1105-8.

21. Giamarellos-Bourboulis EJ, Netea MG, Rovina N, Akinosoglou K, Antoniadou A, Antonakos N, et al. Complex immune dysregulation in COVID-19 patients with severe respiratory failure. Cell Host Microbe. 2020;27(6):992-1000.

22. Magro C, Mulvey JJ, Berlin D, Nuovo G, Salvatore S, Harp J, et al. Complement associated microvascular injury and thrombosis in the pathogenesis of severe COVID-19 infection: a report of five cases. Translat Res. 2020;220:1-3.

23. Bhattacharyya R, Iyer P, Phua GC, Lee JH. The interplay between coagulation and inflammation pathways in COVID-19-associated respiratory failure: a narrative review. Pulmon Ther. 2020;25:17.

24. Dolhnikoff M, Duarte-Neto AN, de Almeida Monteiro RA, da Silva LF, de Oliveira EP, Saldiva $\mathrm{PH}$, et al. Pathological evidence of pulmonary thrombotic phenomena in severe COVID-19. J Thromb Haemost. 2020;18(6):1517-9.

25. Famous KR, Delucchi K, Ware LB, Kangelaris KN, Liu KD, Thompson BT, et al. Acute respiratory distress syndrome subphenotypes respond differently to randomized fluid management strategy. Am J Respir Crit Care Med. 2017;195(3):331-8.

26. Calfee CS, Delucchi K, Parsons PE, Thompson BT, Ware LB, Matthay MA, et al. Subphenotypes in acute respiratory distress syndrome: latent class analysis of data from two randomized controlled trials. Lancet Respir Med. 2014;2(8):611-20.

27. Pan C, Chen L, Lu C, Zhang W, Xia JA, Sklar MC, et al. Lung recruitability in COVID-19 associated acute respiratory distress syndrome: a single-center observational study. Am J Respir Crit Care Med. 2020;201(10):1294-7.
28. Bos LD, Paulus F, Vlaar AP, Beenen LF, Schultz MJ. Subphenotyping ARDS in COVID-19 patients: consequences for ventilator management. Ann Am Thorac Soc. 2020;10:52-9.

29. Barrot L, Asfar P, Mauny F, Winiszewski H, Montini F, Badie J, et al. Liberal or conservative oxygen therapy for acute respiratory distress syndrome. New Eng J Med. 2020;382(11):9991008.

30. Alhazzani W, Møller MH, Arabi YM, Loeb M, Gong MN, Fan E. Sepsis campaign: guidelines on the management of critically ill adults with coronavirus disease 2019 (COVID-19). Intens Cara Med. 2020;54:63-9.

31. Wilcox SR. Management of respiratory failure due to covid-19. BMJ. 2020;369:m1786.

32. Brochard L, Slutsky A, Pesenti A. Mechanical ventilation to minimize progression of lung injury in acute respiratory failure. Am J Respir Crit Care Med. 2017;195(4):438-42.

33. Bellani G, Laffey JG, Pham T, Madotto F, Fan E, Brochard L, et al. Non-invasive ventilation of patients with acute respiratory distress syndrome. Insights from the LUNG SAFE study. Am J Respir Crit Care Med. 2017;195(1):67-77.

34. Wax RS, Christian MD. Practical recommendations for critical care and anesthesiology teams caring for novel coronavirus (2019-nCoV) patients. Can J Anesth. 2020;67(5):568-76.

35. Gattinoni L, Coppola S, Cressoni M, Busana M, Rossi S, Chiumello D. COVID-19 does not lead to a "typical" acute respiratory distress syndrome. American journal of respiratory and critical care medicine. 2020;201(10):1299-300.

36. Fan E, Brodie D, Slutsky AS. Acute respiratory distress syndrome: advances in diagnosis and treatment. JAMA. 2018;319(7):698-710.

37. Tran K, Cimon K, Severn M, Pessoa-Silva CL, Conly J. Aerosol generating procedures and risk of transmission of acute respiratory infections to healthcare workers: a systematic review. PloS one. 2012;7(4):e35797.

38. National health commission of the People's Republic of China. Diagnosis and treatment protocol for COVID-19. Available at: http://en.nhc.gov. cn/2020-09/07/c_81565.htm. Accessed on 30 March 2021.

39. Hong KH, Lee SW, Kim TS, Huh HJ, Lee J, Kim SY, et al. Guidelines for laboratory diagnosis of coronavirus disease 2019 (COVID-19) in Korea. Ann Lab Med. 2020;40(5):351-60.

40. Chen C, Qi F, Shi K, Li Y, Li J, Chen Y, et al. Thalidomide combined with low-dose short-term glucocorticoid in the treatment of critical Coronavirus Disease 2019. Clin Transl Med. 2020;10(2):e35.

41. Lamontagne F, Rochwerg B, Lytvyn L, Guyatt GH, Møller MH, Annane D, et al. Corticosteroid therapy for sepsis: a clinical practice guideline. BMJ. 2018;10:362-5. 
42. Weiss P, Murdoch DR. Clinical course and mortality risk of severe COVID-19. Lancet. 2020;395(10229):1014-5.

43. Higher mortality rate in ventilated COVID-19 patients in large sample. Available at: https://www.medscape. com/viewarticle/928605. Accessed on 30 March 2021.

Cite this article as: Alshaer OR, Binobaid AO, Saleh RM, Eldabbari AA, Aldawsari NI, Alasmari MM, et al. Management of cases of COVID-19 infection with acute respiratory failure: a narrative review. Int $\mathrm{J}$ Community Med Public Health 2021;8:3127-32. 